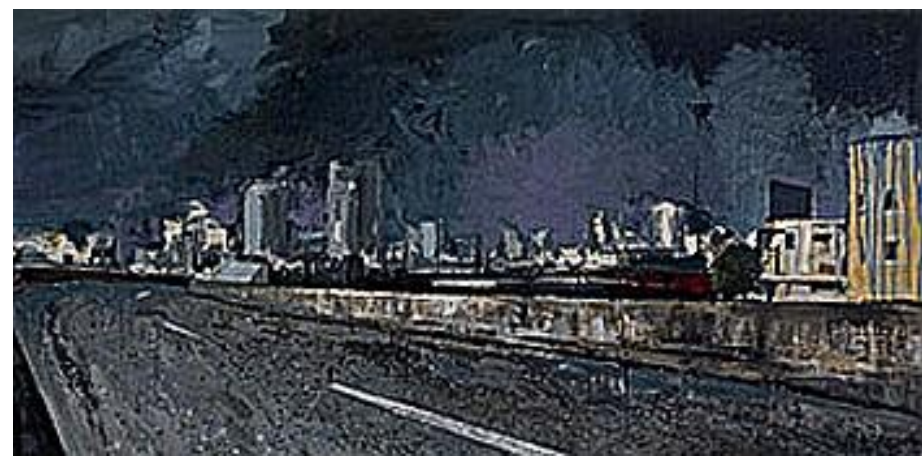

Ilustração Rodrigo Freitas

\title{
o que seriam as geografias de cinema?
}

\section{Wenceslao Machado de Oliveira Jr.}

Wenceslao M. Oliveira Jr é doutor em Educação pela Faculdade de Educação da UNICAMP, professor no Departamento Educação, Conhecimento, Linguagem e Arte desta mesma Faculdade, onde é pesquisador do Laboratório de Estudos Audiovisuais-OLHO.

\section{Resumo}

Este texto constitui-se de escritos que visam a apresentar uma proposta de pesquisa com as imagens e os sons do cinema, apontando para a criação de geografias oriundas do encontro entre os universos culturais de cada um de nós e as imagens e os sons de cada filme.

Palavras-chave: cinema, geografia, pesquisa.

Nestes tempos iniciais de dar forma [ou talvez, melhor dizendo, de dar nome] aos estudos e escritos que venho realizando nos últimos anos, encontrei duas maneiras de pensar as geografias de cinema. De cada uma delas, surgem geografias de cinema distintas. No entanto, no mais das vezes, elas se fazem mutuamente.

Tanto uma quanto outra destas supostas geografias que existem potencialmente nos filmes cinematográficos, ganham existência em produções textuais assentadas nas imagens e sons, 
seqüências e sentidos que os filmes nos apresentam em sua manifestação como arte e indústria.

Elas seriam, uma ou outra, construções imaginativas e interpretativas que se dão numa "região nebulosa" em que os universos culturais das pessoas são sugados para o interior da narrativa fílmica e esta ao interior desses universos culturais. Condensação de imagens: memórias adensadas em torno de sentidos, sentidos adensados em torno de imagens. A geografias de cinema seriam os estudos e os encontros com a dimensão espacial na qual os personagens de um filme agem. Um espaço composto de territórios, paisagens e metáforas: dentro e fora, amplo e restrito, subir e descer, movimentos diagonais, fronteiras diversas, percursos por estradas, rios e oceanos interiores, ambientes simbólicos traduzidos em florestas, desertos, montanhas, cidades...

Essa é uma proposta de pesquisa das imagens e sons fílmicos, baseada na idéia de que os filmes estão a nos propor pensamentos acerca do espaço, não só resultantes das alusões literais - por verossimilhança visual e sonora - a uma realidade existente além cinema, mas também de movimentos imaginativos resultantes do encontro inusitado nessas imagens e sons de outras formas de conceber e viver o espaço como dimensão da existência humana.

Estas geografias de cinema não são produções somente subjetivas e imaginativas, pois elas estão amparadas nas imagens e sons do filme, que são objetivas em sua materialidade de imagens. Da mesma forma não há nada a se retirar destas imagens e sons, pois nesse verbo encontra-se a idéia de que há coisas a serem dali re-tiradas (ou seja, que ali foram postas...) e a nós caberia construir instrumentos (teóricos, sobretudo) que nos permitiria realizar essa tarefa de tirar dali o que ali foi posto por outrem.

A idéia das geografias de cinema é de que somos nós que "colocamos" nas imagens e sons os sentidos que terão nessa interpretação espacializada das obras cinematográficas. O verbo colocar não está aí na acepção deliberada e ativa que costumamos lhe dar, mas contém em si, junto a essa acepção, também uma boa dose de passividade e acaso que o aproxima da idéia de que estes sentidos colocados por nós nas imagens e sons fílmicos nos são "tomados" pelas e com estas imagens e sons. Praticamente estou a dizer que, na verdade, são as imagens e sons que re-tiram de nós coisas e não o contrário... mas não é bem assim... há tensões e sobressaltos, negações e 
tédios, vazios de sentidos que também permeiam o nosso estar diante da tela que nos apresenta luzes, sombras e cores as quais nos chegam como formas, sentidos e afetos... enfim, memórias.

o "encontro" com uma geografia de um filme não é a descoberta daquilo que está por trás das suas imagens e sons, pois a idéia de que exista algo por trás das coisas é ligada a de que exista um sentido último (uma essência) nessas coisas, no caso, as imagens (paisagens...) dos filmes. Não é essa a proposição que faço, mas a de que o conhecimento acerca das coisas se dá não propriamente nelas, mas no encontro entre elas e o que existe em nós, que as imagens e sons fílmicos "sugam"/mobilizam certas memórias em seu "entendimento", e ao mesmo tempo que o faz cria, em imagens e sons, memórias do mundo e da existência. Não há nada por trás a ser descoberto, há o encontro, o susto, o encantamento, o desassossego... conhecimentos enfim, a um só tempo tirados e postos em nós por e com as imagens e sons fílmicos.

Nesta perspectiva de pesquisa não devemos olhar o que de geografia tem nos filmes e sim a que geografia eles dão existência. Ao invés de partirmos do princípio de que a geografia já existe e nós a encontramos nas palavras e frases, partir da idéia de que a inventamos/produzimos em meio às imagens e sons. Essa é a proposição que tenho feito, daí que é preciso permitir que a interpretação (subjetiva, em seu limite) permeie a geografia ali encontrada nas imagens e sons, de modo que esse encontro se faça como inventivo e aberto e não definitivo e fechado (interpretação e não resultado) .

Há nas imagens e sons fílmicos permanências históricas, culturais, arquetípicas... que não sabia o produtor delas. Ali estão como vibrações de uma "memória coletiva" dispersa em nossos corpos. Pode ser que reverberem em nós, pode ser que não... Se sim, comporão nossa geografia do filme, se não, talvez venham a compor a geografia que outro nos der a ver no filme e aí então tornar-se-ão ali existentes também pra nós...

Todo filme constitui-se de locais, locais narrativos. Descolados da contigüidade espacial e geográfica da superfície planetária, esses locais estão nos filmes a constituir um outra geografia, alinhavada não mais por contigüidade, mas por continuidade na narrativa fílmica. Será a "descoberta", a "interpretação geográfica" do filme, que dará a estes locais a sua distribuição no território da ficção, a partir da 
geografia gestada nesta interpretação. Desta forma, o território do filme é elaborado pela geografia nele entrevista, encontrada, descrita, imaginada... O território, nos filmes, não pré-existe à geografia, mas pós-existe a ela, ganha dela a sua existência.

Há continuidades entre os lugares geográficos e os locais narrativos. Alusões, amparos de credibilidade, apropriação de memórias... uns estão nos outros. Os primeiros manifestam-se nos segundos em suas materialidades - formas, movimentos, silhuetas, sentidos -, paisagens e memórias; os segundos dobram-se sobre os primeiros uma vez que tornam-se textos que a eles aludem e neles grudam seus sentidos, suas imagens, suas belezas e tensões, iluminando-os (dizendo-os) de outro modo. A realidade de ambos se faz deles próprios, no interior de suas existências: a contigüidade para os lugares e a continuidade para os locais. Mas como contemporaneamente eles se misturam e se contaminam mutualmente, levam a contigüidade dos primeiros ao interior da continuidade dos segundos e vice-versa.

Um filme vai tendo inúmeros locais narrativos, aqueles por onde vão passando os personagens centrais ao longo de sua transformação. Num filme com deslocamentos no espaço, cada lugar onde um personagem está/passa tem um sentido distinto na narrativa, tornando-o um local narrativo, ou seja, onde ocorre algo importante no seu desenvolvimento, na mensagem a ser dada. No entanto, esses locais são dispostos um depois do outro no tempo (ao longo dos anos/meses/dias/horas que 0 personagem vive; ao longo dos segundos, minutos e horas que configuram o filme) e não no espaço.

- cinema recoloca as pessoas nos lugares e espaços. Os territórios cinematográficos são, via de regra, construídos pelos passos e olhares dos personagens. São eles que dão existência - em materialidades e sentidos - aos locais narrativos. A ciência geográfica, preocupada com extensões espaciais maiores que as habituais do cinema, tem sido levada a tomar estas extensões - cidades, campos de cultivo, montanhas, áreas industriais, áreas de risco, países, etc como "entidades" de existência inteira e independente do que há em seus interiores, em seus detalhes e sentidos. A escala do pensamento geográfico tem sido aquela apontada pelo conceito de região (mais recentemente o de rede veio tomar seu lugar). Um conceito que implica em inevitáveis generalizações e aglutinamentos, redutores também inevitáveis da diversidade, 
das tensões, das fissuras existentes em qualquer lugar em seu interior, tanto das regiões quanto das redes.

Para que a existência concreta da vida das pessoas possa se recolocar no centro do pensamento geográfico penso ser fundamental trazer o conceito de lugar como uma "escala valorizada", a do pontual e específico, não repetível. Por hora, tenho assistido ao sugamento do conceito de lugar para o interior de um pensamento global, generalizador por excelência, ao dizer que no lugar temos o global. Subordinação da experiência, concreta e corporal de cada um, às explicações dadas pelos especialistas acadêmicos que ao generalizar, na busca da invenção de conceitos auxiliadores para se entender melhor o mundo no qual vivemos, devem apagar as marcas do inusitado, do ocasional, do distinto, que apesar de diferir continua permanecendo como igual.

Há certamente beleza e importância no conhecimento produzido nos termos e princípios acadêmicos. De maneira alguma o descarto. É ele que produz a crítica mais severa e contundente a esse saber pontual que nos é legado pela experiência. Também ele deve ser entendido como integrando uma diversidade, ao nos propor formas de pensar que generalizam, que nos inserem (ou tentam inserir) num movimento que é também de outros tantos.

Parece que esse, voltando ao início de minha argumentação, é um problema de escala. Perdeu-se a micro-escala da vida de cada um, da experiência concreta e corporal, em nome dos entendimentos gerais que incluem a todos. Seria esse um dos aspectos mais cruéis do pensamento democrático aplicado à produção de conhecimento: ao ter que incluir a todos como participantes de uma mesma sociedade, de um mesmo mundo, excluem-se a maioria deles, sempre diferentes quando olhados de perto, em close-up.

A geografia de um filme seria aquilo que suporta, sustenta, permite e dá sentido às ações e movimentações dos personagens.

A partir da "descoberta" - da "invenção" - dessas geografias em cada filme é que "situamos" os personagens e suas ações naquela narrativa. No entanto, sempre é bom lembrar que foram justamente essas ações que nos deram as "chaves", nos apontaram indícios da nossa interpretação, essa a que venho 
chamando geografia de cinema. Uma vez que encontro outra forma de apresentar ou entender a dimensão espacial presente numa narrativa fílmica, lanço luzes no entendimento das motivações e tensões dos personagens e conseqüentemente no entendimento de minhas identificações ou desassossegos.

Nas geografias de cinema não há que se cuidar pra permanecer no interior das escalas tradicionais de observação propostas e definidas no interior dos estudos acadêmicos da ciência geográfica. Escalas de um pra um e escalas infinitas podem conviver e redefinir as escalas intermediárias arquitetônicas e geográficas, aquelas com que a superfície do planeta é melhor observada e compreendida tradicionalmente. Estamos falando de cinema, e nele as escalas muito pequenas, captadas nos closes e supercloses convivem e remetem a outras escalas, muitas vezes impossíveis aos homens enquanto corpos viventes, mas franqueadas a suas imaginações e devaneios. Escalas zero pra um, eu diria, a escala dos sonhos...

Poderíamos dizer que muitos filmes lidam com escalas surrealistas, onde o micro é surpreendentemente maior que o macro, pois é dentro dele - ou a partir dele - que a imensidão concreta do interior se abre para aquilo que é mais vasto... grandes extensões visuais nos são dadas em closes de uma pele, de uma casca de árvore, de uma parede descascada...

Uma geografia de cinema, num primeiro momento, tem mais haver com o movimento que o filme causa em mim do que com a trama ou - conteúdo geográfico que ele contém ou representa. Na verdade, ela seria algo um pouco distinto, uma vez que não deve assumir uma perspectiva de desenvolvimento subjetivo apenas e, ainda que assim o assuma, deve ter como foco uma ação eminentemente política, portanto pública ou pelo menos voltada a ele. O que quero dizer com isso é que a intenção de produzir geografias de cinema é a de pensar e inventar outras interpretações para o mundo, a de permitir olhares diferenciados e diversificados às coisas do mundo (não só do filme, mas da realidade nele aludida ou encontrada).

As geografias de cinema, frutos de interpretações subjetivas e de pesquisa das imagens e sons fílmicos, buscam desliteralizar as interpretações habituais dadas a estes filmes... por isso terminam sendo uma proposição educativa, além de poética, das obras do cinema. Essa seria a intenção... ou pretensão... ao me dedicar a olhar os filmes buscando neles geografias que tiveram ali sua origem, e que por isso são geografias de cinema. 
Para que estas geografias de cinema não sejam somente reverberações subjetivas, é preciso dizer onde o sentido que nos ficou do filme acontece. Pesquisar as imagens e sons fílmicos e ver se elas e eles lhe revelam ser verdadeiro o que se intuiu primeiramente. Em seguida, ver de que modo elas o fazem. Enfim, é preciso pesquisar as imagens e sons para descobrir onde elas nos geraram o sentido que nos ficou, o território no qual localizamos os personagens, a geografia na qual estes vivem e agem. É preciso pesquisar as imagens e sons para descobrir se nesta pesquisa elas irão gerar ratificações ou retificações... afinal, as geografias de cinema, sejam elas quais forem, devem estar no filme, terem sido produzidas pelo cinema.

\section{Abstract}

This text has as its objective to present a research proposal on the images and sounds of cinema, pointing towards the creation of geographies stemming from the encounter between each one's cultural universe and the images and sounds of films.

Key-words: cinema, geography, research. 